\title{
Особая роль калия в образовании и устойчивости синтетических минералов
}

\section{Годнева М.М.}

Институт химии и технологии редких элементов и минерального сырья им. И.В. Тананаева ФИЦ КНЦ PAH, Anamumbl,m.godneva@ksc.ru

Аннотация. Приведен обзор распространенности и термической устойчивости синтетических минералов комплексных соединений элементов подгруппы титана со щелочными элементами. На основе статистической обработки данных установлена особая роль калия среди щелочных элементов как по наибольшему числу минералов циркония с калием в подгруппе титана, так и по их наименьшей термической устойчивости.

Ключевые слова: подгруппа титана, щелочные элементы, распространенность, термическая устойчивость.

\section{The special role of potassium in the formation and stability of synthetic minerals}

\section{Godneva M.M.}

Tananaev Institute of Chemistry - Subdivision of the Federal Research Centre KSC RAS, Apatity, m.godneva@ksc.ru

\begin{abstract}
The article provides an overview of the prevalence and thermal stability of synthetic minerals of complex compounds of the titanium subgroup elements with alkaline elements. On the basis of statistical data processing, a special role of potassium among alkaline elements is established both with respect to the largest number of zirconium minerals with potassium in the titanium subgroup and with their lowest thermal stability.
\end{abstract}

Key words: subgroup of titanium, alkaline elements, formation, prevalence, thermal stability.

Выделено свыше 300 комплексных соединений элементов подгруппы титана с калием и анионами $\mathrm{F}^{2}, \mathrm{SO}_{4}^{2-}, \mathrm{C}_{2} \mathrm{O}_{4}^{2-}, \mathrm{PO}_{4}^{3-}$ (Воронков и др., 1978; Годнева и Мотов, 1971, 1980; Годнева, 2015; Годнева и др., 2017; Мотов, 2002; Motov and Godneva, 2009). Число (распространенность) рассмотренных соединений изменяется по ряду $\mathrm{Li}<\mathrm{Na}<\mathbf{K}>\mathrm{Rb}<\mathrm{Cs}$ (табл. 1), т. е. наиболее разнообразны калиевые производные, что вызвано, по-видимому, стерическими возможностями катионов, характером ассоциации катиона с анионом (табл. 2), растворимостью сформировавшихся частиц и склонностью к образованию аморфных соединений основного характера. На примере оксалатных соединений было найдено, что замещение щелочного катиона по ряду $\mathrm{K}, \mathrm{Rb}, \mathrm{Cs}$ приводит к возрастанию длины всех водородных связей в структуре и сопровождается увеличением эффективной координации атома металла (Трунов и др., 2009). Для кристаллических ФФЦМ (Ц - Zr; M - Na, K, Rb, Cs) при одинаковых условиях синтеза и монофазности образовавшегося осадка м.о. M/Zr, L/Zr и F/Zr, где $\mathrm{L}$ - ацидолиганд, в целом, не соответствуют изменению ионного радиуса катиона. При этом, если м.o. L/Zr уменьшаются в соответствии с его ионным радиусом, то для $\mathrm{F} / \mathrm{Zr}$ изменение происходит в обратном порядке. В случае образования ФФМеМ в смеси с иной фазой эти ряды могут не соблюдаться за счет диспропорционирования компонентов между фазами.

Известно, что одно из наиболее замечательных и менее всего разъясненных эмпирических обобщений, основанных на фактическом материале современной кристаллографии состоит в резком предпочтении кристаллическим структурам одних пространственных групп перед другими (Урусов и Надежина, 2009). Для простых соединений высоко симметричные группы наиболее частые, чем низко симметричные.

Статистический анализ частот образования соединений в подгруппе титана свидетельствует о наибольшем количестве соединений циркония относительно остальных элементов подгруппы, что может быть объяснено тем, что соединения титана более склонные к гидролизу, а, следовательно, и к полимеризации, состоят из более сложных зачастую аморфных частиц, чем цирконий, что приводит к более высокой и наиболее частой симметрии его соединений. 
Таблица 1. Количество комплексных металлатов циркония (гафния) со щелочными элементами (Годнева и Мотов, 1971, 1980; Годнева, 2015; Годнева и др., 2017; Мотов, 2002; Motov and Godneva, 2009). Table 1. The number of complex metallates of zirconium (hafnium) with alkaline elements.

\begin{tabular}{|c|c|c|c|c|c|c|}
\hline Соединения ${ }^{\mathrm{a}}$ & $\mathrm{Li}$ & $\mathrm{Na}$ & $\mathrm{K}$ & $\mathrm{Rb}$ & $\mathrm{Cs}$ & $\begin{array}{c}\text { Изменение } \\
\text { количества металлатов }\end{array}$ \\
\hline \multicolumn{7}{|c|}{ Фторометаллаты } \\
\hline средние & 4 & 11 & 45 & 5 & 8 & $\mathrm{Li}<\mathrm{Na}<\mathrm{K}>\mathrm{Rb}<\mathrm{Cs}$ \\
\hline основные & 0 & 1 & 16 & 1 & 1 & $\mathrm{Li}<\mathrm{Na}<\mathrm{K}>\mathrm{Rb}=\mathrm{Cs}$ \\
\hline модификации & 2 & 0 & 6 & 0 & 2 & $\mathrm{Li}>\mathrm{Na}<\mathrm{K}>\mathrm{Rb}<\mathrm{Cs}$ \\
\hline Всего & 4 & 12 & 61 & 6 & 9 & $\mathrm{Li}<\mathrm{Na}<\mathrm{K}>\mathrm{Rb}<\mathrm{Cs}$ \\
\hline \multicolumn{7}{|c|}{ Фторосульфатометаллаты } \\
\hline средние & 0 & 3 & 34 & 3 & 3 & $\mathrm{Li}<\mathrm{Na}<\mathrm{K}>\mathrm{Rb}=\mathrm{Cs}$ \\
\hline основные & 0 & 0 & 23 & 1 & 1 & $\mathrm{Li}=\mathrm{Na}<\mathrm{K}>\mathrm{Rb}=\mathrm{Cs}$ \\
\hline модификации & 0 & 2 & 19 & 0 & 0 & $\mathrm{Li}<\mathrm{Na}<\mathrm{K}>\mathrm{Rb}=\mathrm{Cs}$ \\
\hline Всего & 0 & 3 & 57 & 4 & 4 & $\mathrm{Li}<\mathrm{Na}<\mathrm{K}>\mathrm{Rb}=\mathrm{Cs}$ \\
\hline \multicolumn{7}{|c|}{ Сульфатометаллаты } \\
\hline средние & 0 & 8 & 11 & 6 & 3 & $\mathrm{Li}<\mathrm{Na}<\mathrm{K}>\mathrm{Rb}>\mathrm{Cs}$ \\
\hline основные & 0 & 4 & 43 & 2 & 2 & $\mathrm{Li}<\mathrm{Na}<\mathrm{K}>\mathrm{Rb}=\mathrm{Cs}$ \\
\hline модификации & 0 & 0 & 13 & 0 & 0 & $\mathrm{Li}=\mathrm{Na}<\mathrm{K}>\mathrm{Rb}=\mathrm{Cs}$ \\
\hline Всего & 0 & 12 & 54 & 8 & 5 & $\mathrm{Li}<\mathrm{Na}<\mathrm{K}>\mathrm{Rb}>\mathrm{Cs}$ \\
\hline \multicolumn{7}{|c|}{ Фторофосфатометаллаты } \\
\hline средние & - & 2 & 5 & 3 & 6 & $\mathrm{Na}<\mathrm{K}>\mathrm{Rb}<\mathrm{Cs}$ \\
\hline основные & - & 1 & 5 & 1 & 3 & $\mathrm{Na}<\mathrm{K}>\mathrm{Rb}<\mathrm{Cs}$ \\
\hline модификации & - & 0 & 0 & 0 & 1 & $\mathrm{Rb}<\mathrm{Cs}$ \\
\hline Всего & - & 3 & 10 & 4 & 9 & $\mathrm{Na}<\mathrm{K}>\mathrm{Rb}<\mathrm{Cs}$ \\
\hline Общее число соединений & 4 & 30 & 182 & 22 & 27 & $\mathrm{Li}<\mathrm{Na}<\mathrm{K}>\mathrm{Rb}<\mathrm{Cs}$ \\
\hline
\end{tabular}

Примечание. ${ }^{\text {a/ }}$ выделены из водных растворов. Полужирным шрифтом отмечены максимальные значения.

Таблица 2. Гексафтороцирконаты щелочных металлов (Воронков и др., 1978).

Table 2. Alkali metal hexafluorozirconates.

\begin{tabular}{|c|c|c|c|c|}
\hline Соединение & Радиус катиона $\mathrm{M}^{\mathrm{I}}, \AA$ & К.ч. $\mathrm{Zr}$ & Форма Zr-полиэдра & $\begin{array}{c}\text { Характер ассоциации } \\
\mathrm{Zr-полиэдров}\end{array}$ \\
\hline $\mathrm{Li}_{2} \mathrm{ZrF}_{6}$ & 0.68 & 6 & Октаэдр & $\mathrm{M}$ \\
\hline $\mathrm{Na}_{2} \mathrm{ZrF}_{6}$ & 0.97 & 7 & Октаэдр & Д \\
\hline $\mathrm{K}_{2} \mathrm{ZrF}_{6}$ & 1.33 & 8 & Додекаэдр & Ц \\
\hline $\mathrm{Rb}_{2} \mathrm{ZrF}_{6}$ & 1.47 & 6 & Октаэдр & $\mathrm{M}$ \\
\hline $\mathrm{Cs}_{2} \mathrm{ZrF}_{6}$ & 1.67 & 6 & Октаэдр & $\mathrm{M}$ \\
\hline
\end{tabular}

Примечание. М - мономер, Д - димер, Ц - цепь.

Пространственные группы, которые содержат точечные конфигурации с высокой симметрией, должны иметь преимущество в распространенности (Урусов и Надежина, 2009).

Объяснение резкой неравноценности распространения соединений элементов - сложная и комплексная проблема. Она не может быть объяснена только геометрическим подходом. Требуется также анализ устойчивости кристаллических структур с позиций минимума потенциальной энергии межатомных взаимодействий.

На термическую устойчивость (ТУ) минералов влияют внешнесферные одновалентные катионы (табл. 3), по-видимому, в связи с поляризующим действием катиона на анион. Для гептафто- 


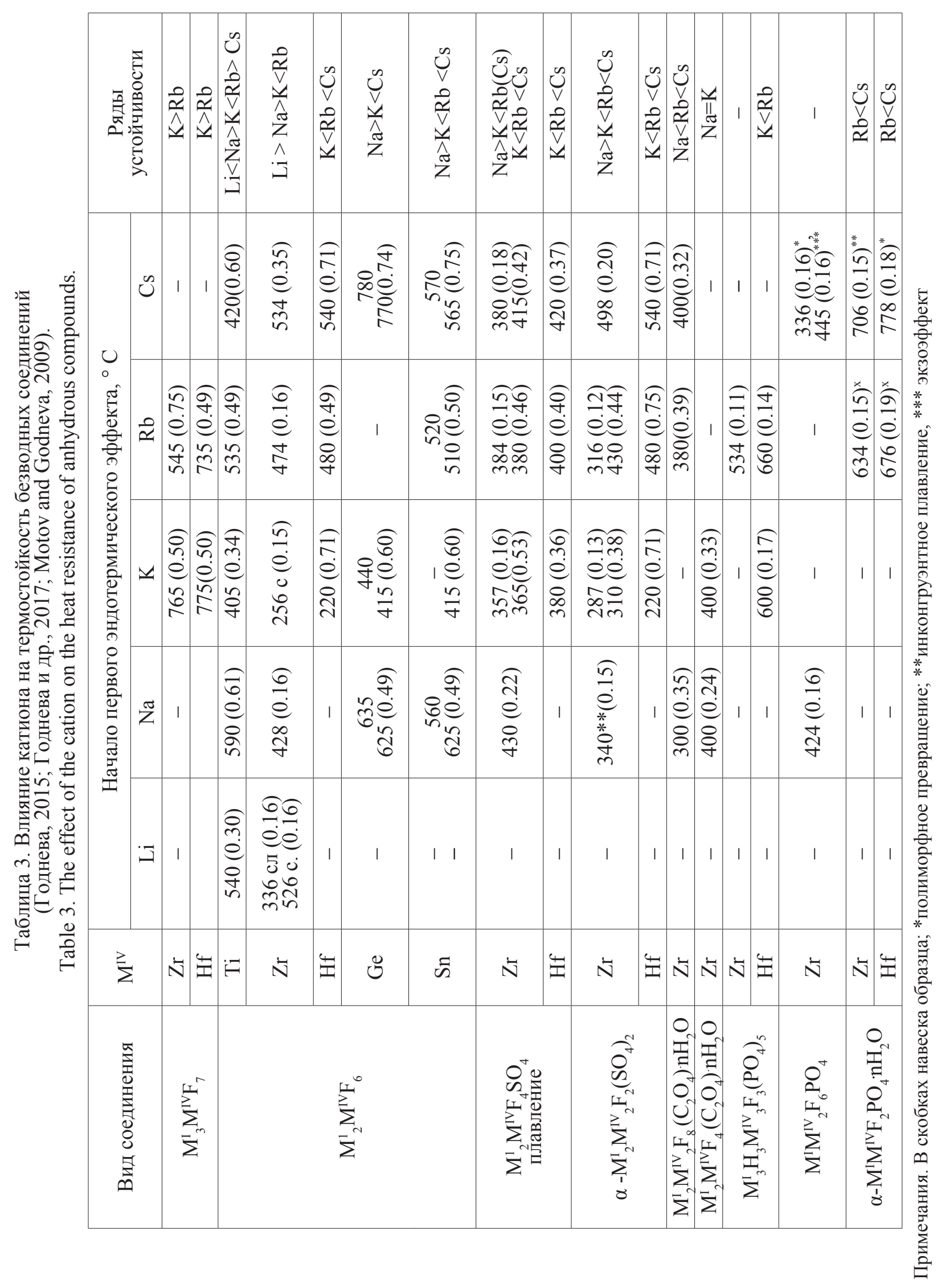


рометаллатов, имеющих островную структуру, калиевые соединения устойчивей рубидиевых. Ранее было отмечено, что соединения, имеющие островную структуру, термически более устойчивы, чем соединения с иным строением (Урусов и Надежина, 2009). Для гесафторометаллатов и ФСМе такого же типа ТУ изменяется по ряду $\mathbf{L i}>\mathbf{N a}>\mathrm{K}<\mathrm{Rb}<\mathrm{Cs}$. Для четырехвалентных Ge и $\mathrm{Sn}$ этот ряд близок к ряду для соединений с $\mathrm{Zr}(\mathrm{Hf}) \mathbf{L i}<\mathbf{N a}>\mathrm{K}<\mathrm{Rb}<\mathrm{Cs}$. Однако он не соблюдается для гексатитанатов $(\mathrm{Li}<\mathrm{Na}>\mathrm{K}<\mathbf{R b}>\mathbf{C s})$. Зависимость ТУ от щелочного металла имеет место не только для минералов со фтором и сульфатной группой, но, по-видимому, и для фторооксалатов и фторофосфатов.

Концентрация фосфорной кислоты, при которой не наблюдалось осадков, а также степень осаждения и прочность фосфатов при введении в фосфорнокислые растворы титана солей щелочных металлов определяются не только концентрацией осадителя и фосфорной кислоты, а также порядковым номером щелочного элемента (Шарова и др., 1974). Причем прочность выделенных соединений возрастает от К к Cs, что, в основном, согласуется с ТУ (табл. 3).

Несмотря на то, что количество соединений циркония с калием относительно соединений с другими щелочными элементами и в подгруппе титана наибольшее, их ТУ, в основном, наименьшая. Полученные данные как автором, так и в литературе по сопоставлению влияния щелочных элементов на свойства соединений свидетельствуют об особой роли среди них калия.

\section{Литература}

1. Воронков А.А., Шумяцкая Н.Г., Пятенко Ю.А. Кристаллохимия минералов циркония и их искусственных аналогов. М.: Наука. 1978. 182 с.

2. Годнева М.М. Химия подгруппы титана: фториды, фосфаты, фторофосфаты из водных сред. Апатиты: Издание КНЦ РАН. 2015. 222 c.

3. Годнева М.М., Мотов Д.Л. Химия фтористых соединений циркония и гафния. Л.: Наука. 1971. 112 с.

4. $\quad$ Годнева М.М., Мотов Д.Л. Химия подгруппы титана: сульфаты и их растворы. Л.: Наука. 1980. 175 с.

5. Годнева М.М., Михайлова Н.Л., Кузнецов В.Я. Залкинд О.А., Борозновская Н.Н. Термическая устойчивость и рентгенолюминесцентные свойства фторооксалатоцирконатов калия // Журн. неорган. химии. 2017. Т. 62. № 6. С. 847-858.

6. Мотов Д.Л. Физико-химия и сульфатная технология титано-редкометалльного сырья. Апатиты: Изд-во Кольского научного центра. 2002. Ч. 1. 189 с.

7. Трунов В.К., Ефремов В.А., Цхелышвили Н.Б. Сравнительный анализ строения дигидратов гидрооксалатов калия, рубидия и цезия // Журн. структур. химии. 1990. Т. 31 № 5. С. 19-24.

8. Урусов В.С., Надежина Т.Н. Частотное распределение и «селекция» пространственных групп в неорганической кристаллохимии // Журн. структ. химии. Приложение. 2009. Юбилейный Т. 50. С. 26-43.

9. Шарова А.К., Фотиев А.А., Крылов Е.Н., Штин А.П., Бамбуров В.Г., Полякова В.М. Синтез и свойства соединений ниобия, тантала и титана. М.: Наука (отв. редактор Г.П. Швейкин). Тр. Урал. н. центра АН CCCP. 1974. 315 c.

10. Motov D.L., Godneva M.M. Fluoric, Sulfatic and Fluorosulfatic Compounds of Group IV Elements: Forming \& Properties. Nauka. SPb. 2009. 307 p. [Химия подгруппы титана: сульфаты, фториды, фторосульфаты из водных сред. М: Наука. 2006. 302 с.]. 